\title{
DETERMINATION OF FLUCONAZOLE AND ITS OXIDATION PRODUCTS WITH KINETIC EVALUATION UNDER POTASSIUM PERMANGANATE TREATMENT IN ACIDIC SOLUTIONS BY ULTRA PERFORMANCE LIQUID CHROMATOGRAPHY-TANDEM MASS SPECTROMETRY
}

\author{
URSZULA HUBICKA ${ }^{1}$, JAN KRZEK'1, PAWEŁ ŻMUDZKI ${ }^{2}$, \\ BARBARA ŻUROMSKA-WITEK ${ }^{1}$, DARIUSZ MOTYL ${ }^{1}$ and AGATA KRYCZYK ${ }^{1 *}$ \\ 'Department of Inorganic and Analytical Chemistry, Faculty of Pharmacy, \\ Jagiellonian University Medical College, Kraków, Poland \\ ${ }^{2}$ Department of Medicinal Chemistry, Faculty of Pharmacy, \\ Jagiellonian University Medical College, Kraków, Poland
}

\begin{abstract}
For the determination of fluconazole (FLU) oxidation stability under permanganate treatment at the acidic $\mathrm{pH}$, a sensitive, reproducible, and stability-indicating ultra-performance liquid chromatography-mass spectrometry (UPLC/MS) method was developed. Three additional products $\left(t_{R}=5.79,6.98,7.54\right)$ were observed besides the FLU $\left(t_{R}=6.22\right)$. The proposed method was used to study the kinetics of FLU oxidative degradation. An oxidation process followed the kinetics of the second-order reaction. The degradation rate constant and the corresponding half-life obtained for the FLU oxidative degradation were $0.5626 \mathrm{~h}^{-1}$ and $16.69 \mathrm{~h}$, respectively. The putative oxidation products were characterized and their fragmentation pathways, on a basis of MS/MS data, were proposed.
\end{abstract}

Keywords: fluconazole, stability, oxidation studies, kinetic evaluation, UPLC/MS

Fluconazole (FLU), [2-(2-4-difluorophenyl]1,3-bis(1H-1,2,4-triazol-1-yl)propan-2-ol], a synthetic antifungal agent of the imidazole class, is systemically used in oral, esophageal, and vaginal candidiasis, as well as in the treatment of cryptococcal infections in patients with the acquired immunodeficiency syndrome (AIDS). FLU interacts with 14- $\alpha$ demethylase, a cytochrome P-450 enzyme necessary to convert lanosterol to ergosterol-an essential component of the fungal cell membrane. Fluconazole is eliminated primarily by renal excretion, with approximately $80 \%$ of the administered dose appearing in the urine as unchanged drug (1-3).

Different analytical methods, for example, spectrophotometry $(4,5)$; capillary electrophoresis (6); micellar electrokinetic capillary chromatography (7); RP-HPLC (1, 3, 8), UPLC (9), or UPLCMS/MS (10); and gas chromatography (11, 12), were reported for the determination of FLU in pharmaceutical preparations and biological matrices.

The stability of active pharmaceutical ingredients (APIs) affects quality, efficacy and usage safe- ty of APIs. The chemical and physical stability evaluation process consists of many tests. These tests should be conducted in a planned way following the guidelines issued by ICH, WHO, or FDA (13-15). The most important stability tests are stress tests, which enable to identify degradation products. A list of stress factors suggested for forced degradation studies must include acid and base hydrolysis, thermal degradation, photolysis, and oxidation (13). The regulations do not specify the oxidation agents, which should be used, in the case of oxidation. A $0.1-3 \%$ solutions of hydrogen peroxide are widely used in forced degradation studies. Other chemicals useful in oxidation reactions include, for example, potassium permanganate $\left(\mathrm{KMnO}_{4}\right)$, sodium hypochlorite, singlet oxygen, or Fenton's reagent (16).

$\mathrm{KMnO}_{4}$ is widely used as an oxidizing agent in synthetic and in analytical chemistry and is also applied as a disinfectant. It is effective over a wide $\mathrm{pH}$ range. Potassium permanganate is the most potent oxidation state both in alkaline and in acid

\footnotetext{
* Corresponding author: e-mail: agata.kryczyk@uj.edu.pl
} 
mediums. $\mathrm{KMnO}_{4}$ can be used to differentiate degradation products that can be related to drug and its degradation products. Oxidation by permanganate ion is applied in organic syntheses since the advent of phase-transfer catalysis $(17,18)$.

There are reports in which FLU was subjected to stress conditions of acid, alkali, and neutral hydrolysis; oxidation; photolysis (in solutions and solid phase); and thermal decomposition by RPHPLC. Extensive degradation was found to occur in oxidative medium under thermal stress (19). The forced oxidation degradation of FLU using hydrogen peroxide by spectrophotometric method was performed (2). The literature survey also evidenced the results of the stability of reconstituted FLU oral suspension (20).

Shortage of information concerning reaction of FLU with oxidants prompted us to investigate the influence of $\mathrm{KMnO}_{4}$ on this drug stability. Herein, we report on the development of a new UPLCMS/MS method for the determination of FLU and its oxidation products during reaction with $\mathrm{KMnO}_{4}$ at the acidic $\mathrm{pH}$. The method was used for kinetic studies and identification of obtained degradation products of FLU.

\section{Chemicals and methods \\ Chemicals and reagents}

Fluconazole; 99.35\%, SlovakoFarma, Batch 00/1040/01. HPLC grade glacial acetic acid was purchased from AppliChem (Germany). HPLC grade acetonitrile and formic acid (98\%) were purchased from J.T. Baker. HPLC grade water was obtained from HLP 5 (HYDROLAB Poland) apparatus and was filtered through $0.2 \mu \mathrm{m}$ filter before use.

\section{Standard solution}

The amount of $50.8 \mathrm{mg}$ of FLU, weighed with a precision of $0.1 \mathrm{mg}$, was dissolved in the volume of $2.5 \mathrm{~mL}$ of glacial acetic acid and filled (up to the $25 \mathrm{~mL}$ ) with dilution water. For method validation, five solutions with concentration of $0.0609,0.0812$, $0.1015,0.1218$, and $0.1421 \mathrm{mg} / \mathrm{mL}$ of FLU were prepared.

\section{Oxidation study of the drug substance}

The amount of $0.5 \mathrm{~mL}$ of solution of FLU (2.03 $\mathrm{mg} / \mathrm{mL}), 3.5 \mathrm{~mL}$ demineralized water, $1.0 \mathrm{~mL}$ of concentrated sulfuric acid, $5.0 \mathrm{~mL} 0.02 \mathrm{M} \mathrm{KMnO}_{4}$, and $5 \mu \mathrm{L}$ of manganese dioxide solution was added

Table 1. Validation of the method.

\begin{tabular}{|c|c|}
\hline Parameter & Fluconazole \\
\hline $\mathrm{t}_{\mathrm{R}}(\min )$ & $6.22 \pm 0.05$ \\
\hline Limit of detection, $[\mu \mathrm{g} / \mathrm{mL}]$ & 4.10 \\
\hline Limit of quantitation, $[\mu \mathrm{g} / \mathrm{mL}]$ & 12.60 \\
\hline Linearity range, $[\mathrm{mg} / \mathrm{mL}]$ & $0.0609-0.1421$ \\
\hline $\begin{array}{l}\text { Regression coefficients } \\
\mathrm{P}=\mathrm{a} \mathrm{c}+\mathrm{b} \pm \mathrm{S}_{\mathrm{e}}^{\mathrm{b}}\end{array}$ & $\begin{array}{l}\mathrm{a}=4696.7 \\
\mathrm{~b}=6.7240\end{array}$ \\
\hline $\begin{array}{l}\text { Standard deviation of the } \\
\text { regression coefficients }\end{array}$ & $\begin{array}{c}\mathrm{S}_{\mathrm{a}}=53.54194 \\
\mathrm{~S}_{\mathrm{b}}=5.64771\end{array}$ \\
\hline Correlation coefficient, $\mathrm{R}$ & 0.9992 \\
\hline Determination coefficient, $\mathrm{R}^{2}$ & 0.9982 \\
\hline $\begin{array}{l}\text { Normality of residuals } \\
\text { (Shapiro-Wilk test) }\end{array}$ & $0.9493(\mathrm{p}=0.5131)$ \\
\hline Precision (\% RSD) & $\begin{array}{l}\text { level 50\%: } 0.56 \% \\
\text { level 100\%: } 0.63 \% \\
\text { level 150\%: } 0.89 \%\end{array}$ \\
\hline Indirect precision (\% RSD) & $\begin{array}{l}\text { level 50\%: } 0.93 \% \\
\text { level 100\%: } 0.79 \% \\
\text { level 150\%: } 1.02 \%\end{array}$ \\
\hline Recovery $[\%] \mathrm{n}=3$ & $\begin{array}{l}\text { level } 80 \% \text { : } 100.17 \% \\
\text { level 100\%: } 99.67 \% \\
\text { level 120\%: } 98.11 \%\end{array}$ \\
\hline
\end{tabular}

${ }^{\mathrm{a}}$ Mean $\pm \mathrm{SD}(\mathrm{n}=5) .{ }^{\mathrm{b}} \mathrm{P}=$ peak area; $\mathrm{c}=$ concentration; $\mathrm{a}$ and $\mathrm{b}=$ regression coefficients, $\mathrm{S}_{\mathrm{e}}=$ standard error of the estimate, $S_{a}=$ standard deviation of the slope, $S_{b}=$ standard deviation of the intercept, ${ }^{c}$ Normal distribution of residuals if $\mathrm{p}>0.05, \mathrm{RSD}=$ relative standard deviation. 


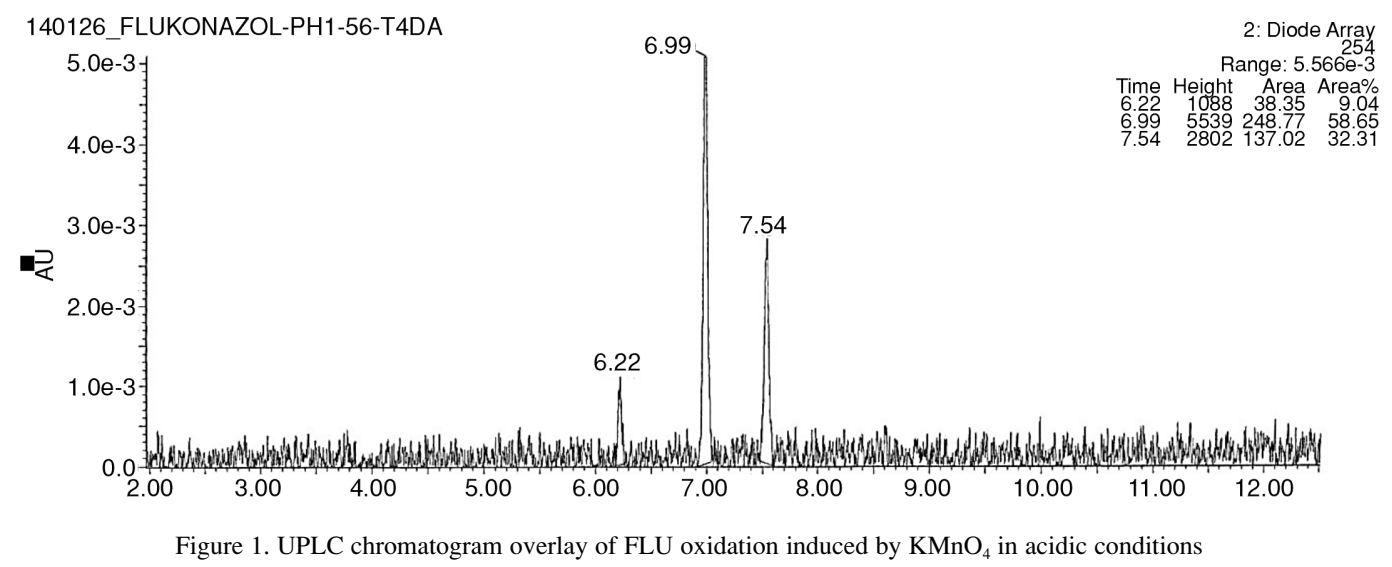

to $10.0 \mathrm{~mL}$ flasks. The test solutions were incubated at room temperature and $1 \mu \mathrm{L}$ of each reaction mixture was injected onto ACQUITY UPLC system after $36,47,54,71$, and $110 \mathrm{~h}$, respectively.

Before the measurements of test samples, the analysis of solutions containing identical components as test samples but without $\mathrm{KMnO}_{4}$ was done. The analyses were performed in triplicate.

\section{UPLC/MS/MS analysis}

The UPLC-MS/MS system consisted of a Waters ACQUITY ${ }^{\circledR}$ UPLC $^{\circledast}$ (Waters Corporation, Milford, MA, USA) coupled to a Waters TQD mass spectrometer (electrospray ionization mode ESI-tandem quadrupole). Chromatographic separations were carried out using the Acquity UPLC BEH (bridged ethyl hybrid) C18 column; $2.1 \times 100 \mathrm{~mm}$, and $1.7 \mu \mathrm{m}$ particle size, equipped with Acquity UPLC BEH C18 VanGuard pre-column; $2.1 \times 5$ $\mathrm{mm}$, and $1.7 \mu \mathrm{m}$ particle size. The column was maintained at $40^{\circ} \mathrm{C}$, and eluted under gradient conditions from $100 \%$ to $50 \%$ of eluent A over $13 \mathrm{~min}$, at a flow rate of $0.3 \mathrm{~mL} / \mathrm{min}$. Eluent $\mathrm{A}: 0.1 \%(\mathrm{v} / \mathrm{v})$ formic acid in water; eluent B: $0.1 \%(\mathrm{v} / \mathrm{v})$ formic acid in acetonitrile. $1 \mu \mathrm{L}$ of each sample was injected. Chromatograms were made using Waters eë PDA detector. Spectra were analyzed in 200-700 $\mathrm{nm}$ range with $1.2 \mathrm{~nm}$ resolution and sampling rate of 20 points/s.

MS detection settings of Waters TQD mass spectrometer were as follows: source temperature $150^{\circ} \mathrm{C}$, desolvation temperature $350^{\circ} \mathrm{C}$, desolvation gas flow rate $600 \mathrm{~L} / \mathrm{h}$, cone gas flow $100 \mathrm{~L} / \mathrm{h}$, capillary potential $3.00 \mathrm{kV}$, cone potential $20 \mathrm{~V}$. Nitrogen was used for both nebulizing and drying gas. The data were obtained in a scan mode ranging from 50 to $1000 \mathrm{~m} / \mathrm{z}$ in time $0.5 \mathrm{~s}$ intervals.
Collision-activated dissociations (CAD) analyses were carried out with the energy of $30 \mathrm{eV}$, and all the fragmentations were observed in the source. Consequently, the ion spectra were obtained by scanning from 50 to $1000 \mathrm{~m} / \mathrm{z}$ range. Data acquisition software was MassLynx V 4.1 (Waters).

\section{Method validation}

The described method was validated for the determination of FLU in the presence of oxidation products by UPLC method according to ICH guidelines (21).

\section{Specificity}

To demonstrate the specificity of the developed UPLC method the solution of FLU after oxidation stress was analyzed. Oxidation study was performed in $\mathrm{KMnO}_{4}$ solution at the acidic $\mathrm{pH}$; the solution was left for $15 \mathrm{~min}$ at room temperature. Peak purity test was carried out for FLU peak by using MS detector in a stressed sample.

\section{Linearity}

The calibration plot for the method was constructed by analysis of five solutions containing different concentrations of FLU in the range $0.0609-0.1421 \mathrm{mg} / \mathrm{mL}$. Solutions were injected into a column in the amounts of $1 \mu \mathrm{L}$. A further analytical procedure was as described in the UPLC Conditions. Linearity was assessed in triplicate on the basis of the relationship between peak areas and concentration, in milligrams per milliliter. The linear coefficients, standard deviation of slope and intercept, correlation coefficient $\mathrm{R}$, determination coefficient $\left(\mathrm{R}^{2}\right)$, standard error of residuals of the calibration curve and to determine whether the residuals have a normal distribution, the Shapiro- 
Wilk statistical test were calculated using the program Statistica v. 10.

\section{Limit of detection (LOD) and limit of quantifica-} tion (LOQ)

Based on the standard error of residuals (Se) and the slope (a) of the calibration plot and following the formula $\mathrm{LOD}=3.3 \mathrm{Se} / \mathrm{a}$ and $\mathrm{LOQ}=10 \mathrm{Se} / \mathrm{a}$, the LOD and LOQ for FLU was estimated.

\section{Precision}

The repeatability of the method was checked by a threefold analysis of the three concentrations levels $0.0508 \mathrm{mg} / \mathrm{mL}, 0.1015 \mathrm{mg} / \mathrm{mL}$ and 0.1523 $\mathrm{mg} / \mathrm{mL}(50 \%, 100 \%$ and $150 \%)$ of FLU solutions. The same protocol was followed for three different days to study the intermediate precision of the proposed method. Different analysts prepared different solutions on different days. The RSD (\%) of the peak area of FLU was calculated.

\section{Accuracy}

The accuracy of the method was evaluated in triplicate $(\mathrm{n}=3)$ at the three concentrations of 0.0812 , 0.1015 and $0.1218 \mathrm{mg} / \mathrm{mL}(80 \%, 100 \%$, and $120 \%)$ of FLU solutions, and the recovery was calculated for each added (externally spiked) concentration.

Table 2. Kinetic results of FLU oxidation by $\mathrm{KMnO}_{4}$ in acidic media at room temperature.

\begin{tabular}{|c|c|c|c|}
\hline $\begin{array}{c}\text { Rate constant, } \\
\mathrm{k}\left[\mathrm{h}^{-1}\right]\end{array}$ & $\begin{array}{c}\mathrm{t}_{0.1} \\
{[\mathrm{~h}]^{\mathrm{a}}}\end{array}$ & $\begin{array}{c}\mathrm{t}_{0.5} \\
{[\mathrm{~h}]^{\mathrm{a}}}\end{array}$ & $\mathrm{R}^{\mathrm{a}}$ \\
\hline 0.5626 & 1.85 & 16.69 & 0.9716 \\
\hline
\end{tabular}

${ }^{\mathrm{a}} \mathrm{t}_{0.5}=$ half-life, $\mathrm{t}_{0.1}=$ time after which $10 \%$ of the substrate decomposes, and $\mathrm{R}=$ correlation coefficient.
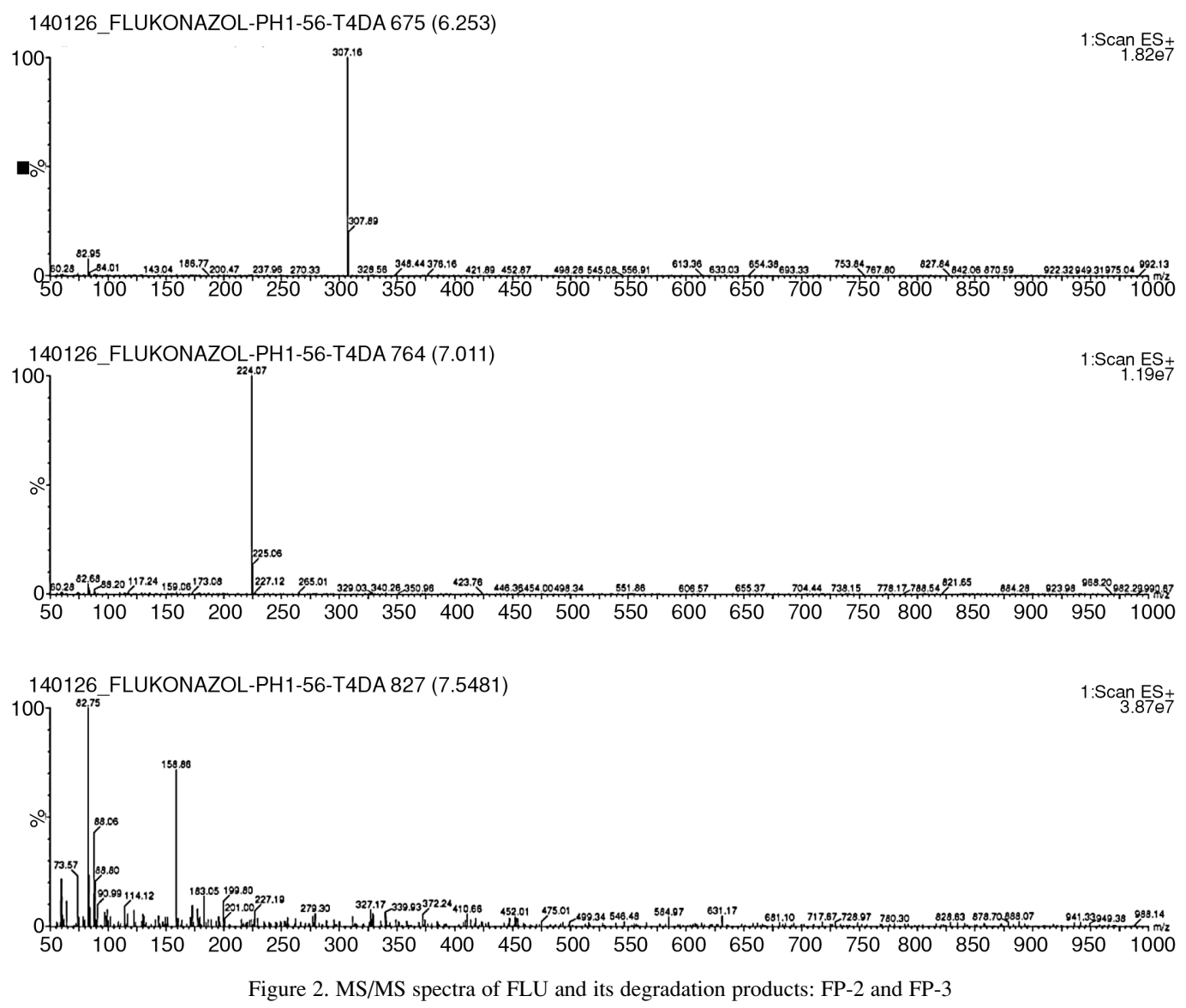


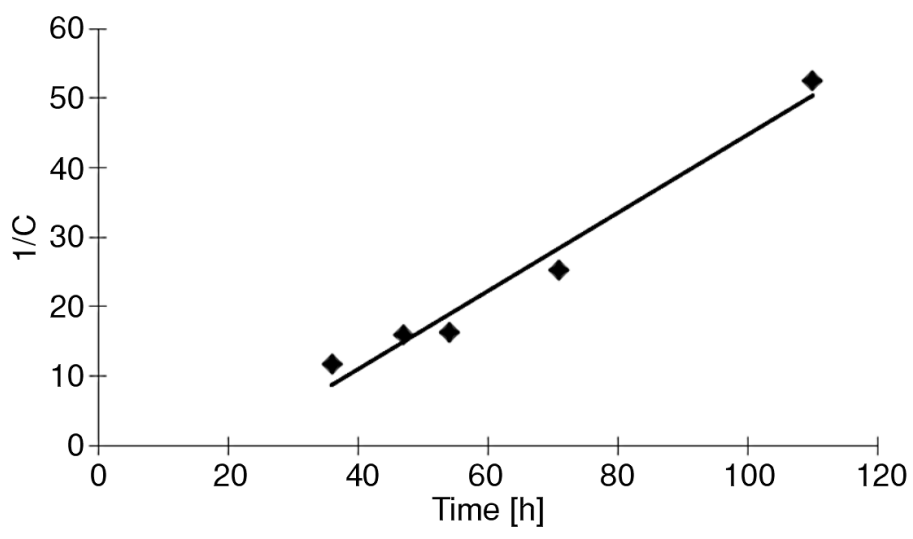

Figure 3. The $1 / \mathrm{c}=\mathrm{f}(\mathrm{t})$ graph of oxidation of FLU by $\mathrm{KMnO}_{4}$ in acidic medium

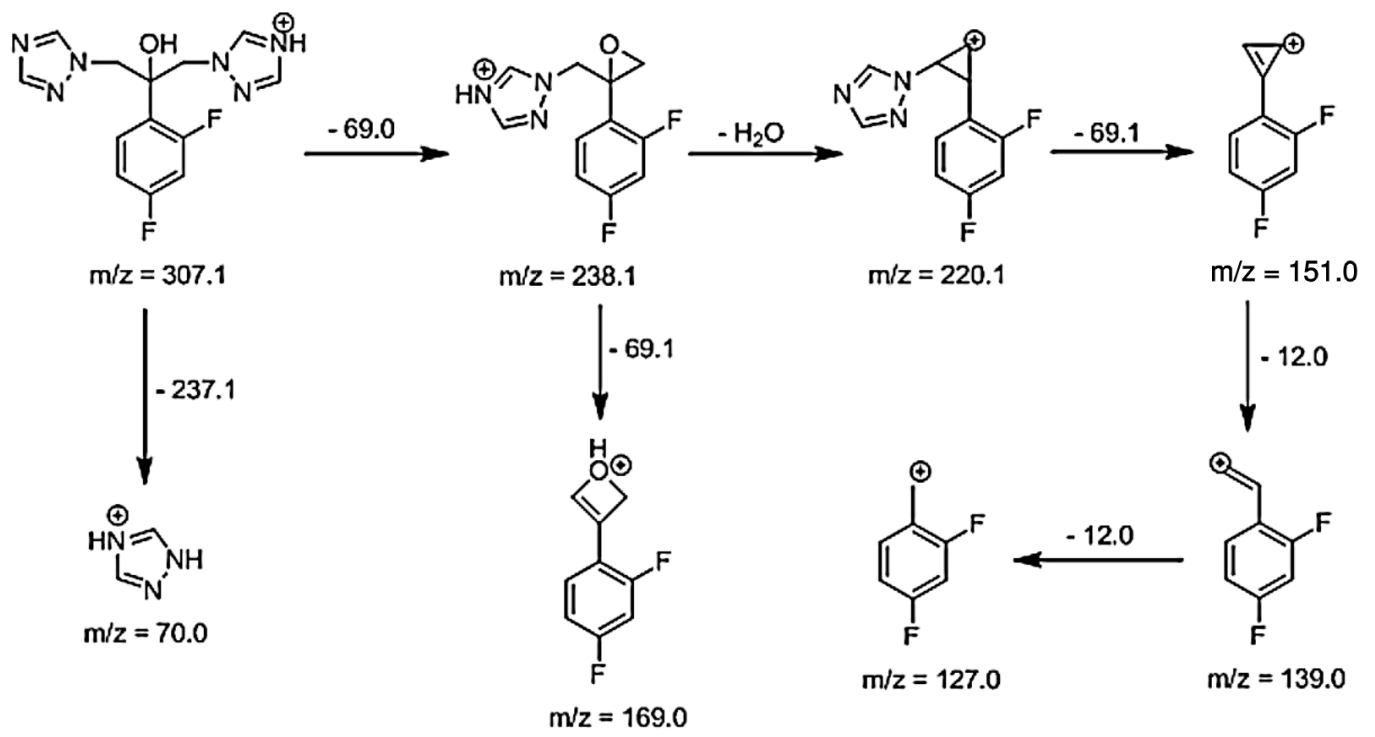

Figure 4. Fragmentation pattern of product FLU

\section{Robustness}

To demonstrate the robustness of the method deliberate small changes of flow rate, the content of acetonitrile and column temperature were made around the optimal values. The mobile phase flow rate was $0.30 \mathrm{~mL} / \mathrm{min}$; to study the effect of the flow rate on the resolution, the flow rate was changed to 0.27 and $0.33 \mathrm{~mL} / \mathrm{min}$. The effect of the column temperature was studied at $36^{\circ} \mathrm{C}$ and $44^{\circ} \mathrm{C}$ (instead of $40^{\circ} \mathrm{C}$ ), and the mobile phase composition was changed $+10 \%$ from the initial composition.

\section{RESULT AND DISCUSSION}

\section{Result and discussion}

ICH guideline requires stress testing to be performed to elucidate the inherent stability characteristics of the active substance (13). Ideal stabilityindicating method is one that quantifies the standard drug alone without any interference from its degradation products. For the separation and identification of examined constituents and for the kinetic studies of FLU in the presence of $\mathrm{KMnO}_{4}$ in acidic 
solution, the developed and validated UPLCMS/MS method is suitable.

\section{Optimization of chromatographic conditions}

The UPLC/MS method was chosen to evaluate the degradation process of FLU under potassium permanganate treatment in an acidic solution. With the development of the chromatographic method enabling the determination of FLU and its oxidation products, a test procedure was started. After oxidation stress, the FLU solution was analyzed. Satisfactory results were achieved using gradient conditions from $100 \%$ to $0 \%$ of water/formic acid $(0.1 \%, \mathrm{v} / \mathrm{v})$ over $13 \mathrm{~min}$ as eluent $\mathrm{A}$ and acetonitrile/formic acid $(0.1 \%, \mathrm{v} / \mathrm{v})$ as eluent $\mathrm{B}$, at a flow rate of $0.3 \mathrm{~mL} / \mathrm{min}$. The retention time for FLU in the developed condition was $\approx 6.22 \mathrm{~min}$.

\section{Method validation}

The developed UPLC method was specific to FLU and guaranteed to obtain well-shaped peaks both for active substance and coexisting oxidation products. Peaks of FLU were well resolved from products FP-1, FP-2, FP-3 in chromatograms, and no interference that could have an influence on the obtained results was observed.

Good linearity was observed in the concentration range $0.0609-0.1421 \mathrm{mg} / \mathrm{mL}$ of FLU. The correlation coefficient and determination coefficient $\left(\mathrm{R}^{2}\right)$ obtained for the linear model were greater than 0.99. The y-intercept of the linear equation for FLU was statistically insignificant. The distribution of the residuals can be approximated with a normal distribution as it is shown by the p-value $(p>0.05)$ of the Shapiro-Wilk normality test. Sensitivity of the method was good. The limit of detection (LOD) and limit of quantification (LOQ) values were found to be 4.10 and $12.60 \mu \mathrm{g} / \mathrm{mL}$, respectively. Accuracy of the method expressed as \% recovery at three concentration levels was from $98.11 \%$ to $100.17 \%$. Good precision and intermediate precision with $\%$ RSD less than $1.02 \%$ was observed. Table 1 presents the detailed results. In all the deliberately varied chromatographic conditions (flow rate, column temperature, mobile phase composition), FLU and

Table 3. Proposed products of degradation of FLU.

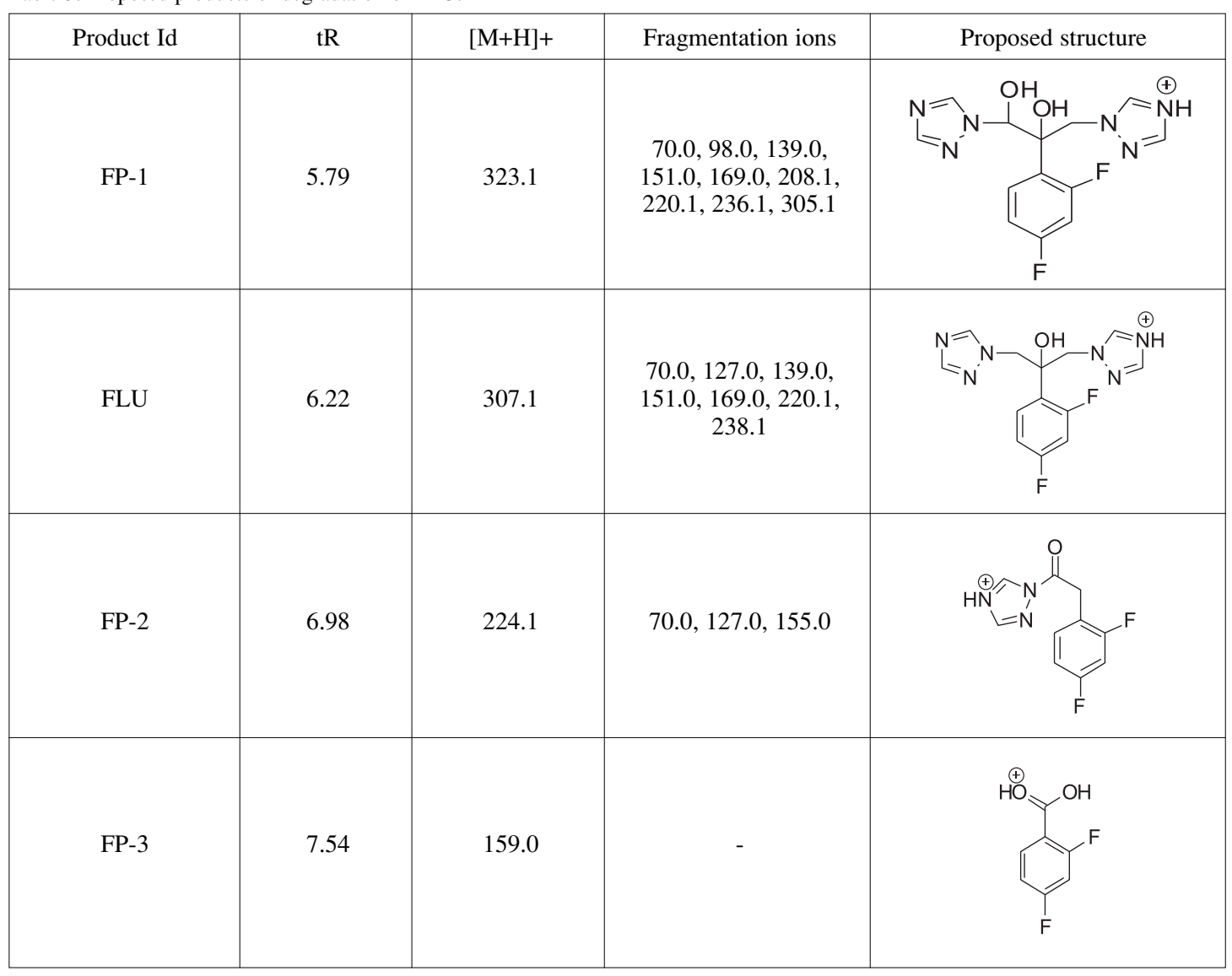




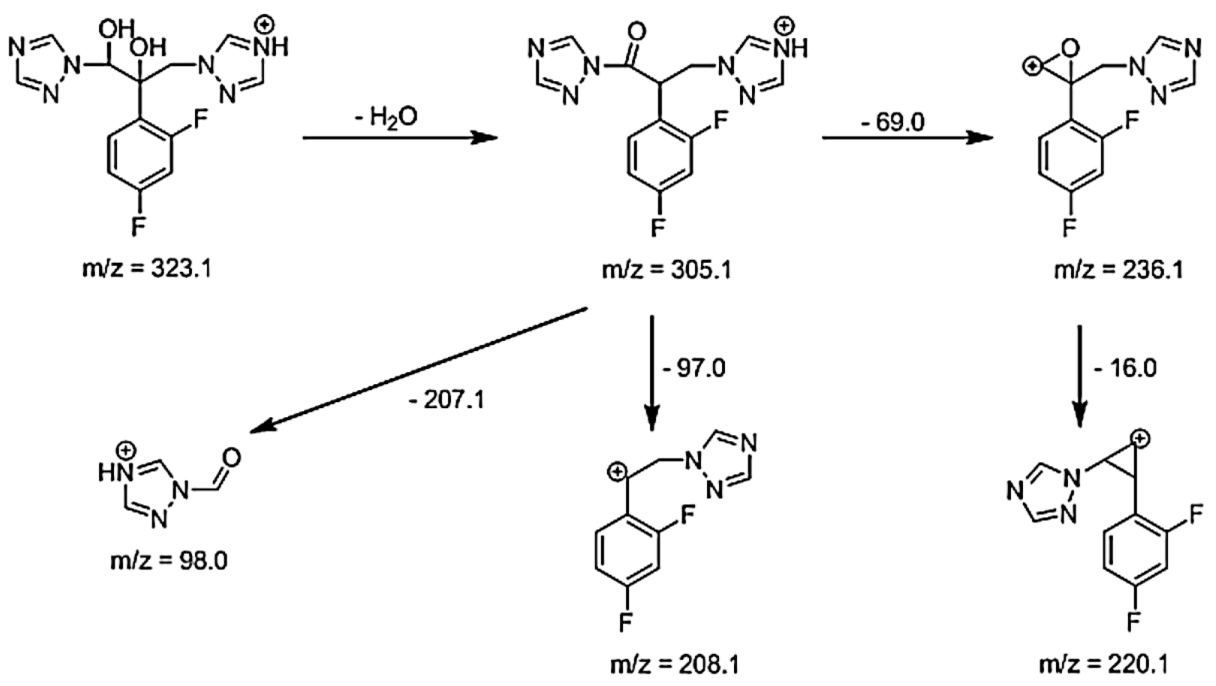

Figure 5. Fragmentation pattern of product FP-1

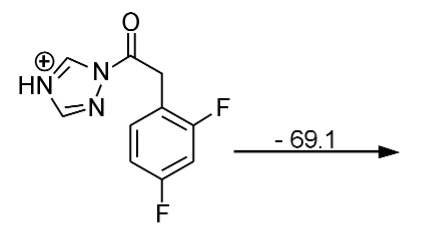

$\mathrm{m} / \mathrm{z}=224.1$

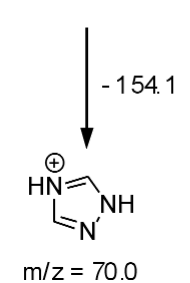

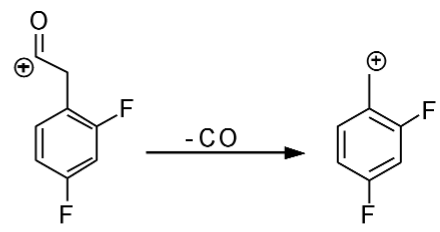

$\mathrm{m} / \mathrm{z}=155.0$

Figure 6. Fragmentation pattern of product FP-2

degradation products were adequately resolved, and the order elution remained unchanged.

\section{Oxidation of $\mathrm{FLU}$ by $\mathrm{KMnO}_{4}$ in acidic medium}

The oxidative ability of $\mathrm{KMnO}_{4}$ depends on the acidity of a reaction solution. The oxidation potential of $\mathrm{KMnO}_{4}$ decreases with increasing $\mathrm{pH}$ value and counts $+1.23 \mathrm{~V}$ at $\mathrm{pH} 3$, and at $\mathrm{pH} 5$, it reaches $+1.07 \mathrm{~V}$; in neutral solution or in basic solution, it was lower and equaled $+0.58 \mathrm{~V}$ and $+0.56 \mathrm{~V}$, respectively (22). Chromatograms obtained for acid solution containing only FLU showed one peak with retention time $t_{R} \approx 6.22 \mathrm{~min}$, whereas in chromatograms obtained for test solutions containing
$\mathrm{KMnO}_{4}$, with the addition of concentrated sulfuric acid, three additional peaks of oxidation products of FLU with retention times such as FP-1 $t_{\mathrm{R}} \approx 5.79$, FP-2 $t_{\mathrm{R}} \approx 6.98$, and FP-3 $\mathrm{t}_{\mathrm{R}} \approx 7.54$ were observed besides peak of $F L U t_{R} \approx 6.22 \mathrm{~min}$ (Fig. 1). Figure 2 presents the MS/MS spectra of FLU and degradation products such as FP-2 and FP-3. The degradation process of FLU increased with the prolongation of incubation time, and after 110 hours, decomposition of FLU was $82.12 \%$.

\section{Kinetic evaluation}

The analysis of the equation $1 / \mathrm{c}=\mathrm{f}(\mathrm{t})$ for the oxidation of FLU induced by $\mathrm{KMnO}_{4}$ under acidic condi- 
tions revealed that the process followed the kinetics of second-order reaction (Fig. 3). Table 2 present the calculated values of $\mathrm{k}, \mathrm{t}_{0.1}$, and $\mathrm{t}_{0.5}$. The linear regression equation was $\mathrm{y}=-11.41 \mathrm{x}+0.5626$. The correlation coefficient and determination coefficient $\left(\mathrm{R}^{2}\right)$ obtained for linear model were found to be 0.9857 and 0.9716 , respectively. The standard deviation of slope and intercept were 0.06 and 3.82 , respectively.

\section{Identification of oxidation products of FLU}

The identification of photodegradation products of fluconazole was performed on a basis of UPLC/MS analysis and supported with fragmentation patterns obtained from MS/MS experiments. The structures of the proposed degradation products are shown in Table 3. The structures of the presented stable products of the degradation were proposed on basis of the results of Collisionally Activated Decomposition (CAD) experiments.

FLU was found at the retention time of 6.22 min with a molecular ion peak of $\mathrm{m} / \mathrm{z} 307$ in the positive mode. Methylene group was most susceptible to oxidation in close vicinity to triazole moiety. Hydroxylation of this group yielded product FP-1. Further oxidation of this compound led to the loss of triazolylmethylene moiety and dehydratation, as it is observed in the case of product FP-2. Finally, degradation of FP-2 involved loss of triazole-1-carbonyl moiety and oxidation of methylene group to carboxylic group, yielding 2,4-difluorobenzoic acid (FP-3). Figures 4-6 show the degradation patterns. This quantity of degradation products found is the largest compared with previously published papers $(2,19)$. The proposed chemical structures of the oxidation products shown in Table 3 are new, compared to those reported in earlier publications. Azole compounds, which are imidazole and triazole derivatives, showed strong differences in their stability (23-26). One of the most possible routs of degradation of azole antifungal drugs is hydroxylation that can result in the ring opening or loss of imidazole moiety as observed for, for example, clotrimazole or bifonazole $(23,24)$. Similarly, in this case, hydroxylation was the first step in the oxidative degradation of FLU leading to FP-1. The product FP-2 at a retention time of $6.98 \mathrm{~min}$ and the molecular ion peak $(\mathrm{m} / \mathrm{z} 224)$ were the consequences of further hydroxylation, which resulted in loss of one of triazole ring.

\section{CONCLUSIONS}

We have developed new stability indicating UPLC-MS/MS method for the determination of FLU and its oxidation products. The method meets the acceptance criteria for validation and may be used for the kinetic analysis of FLU oxidation. The process followed kinetics of the second-order reaction for the substrate. Finally, MS/MS experiments allowed to determine that FLU oxidation results in three derivatives.

\section{REFERENCES}

1. Abdel-Moetty E.M., Khattab F.I., Kelani K.M., AbouAl-Alamein A.M.: Farmaco 57, 931 (2002).

2. Lotfy H.M., Monir H.H., Abd El-Aleem A.E.E.: J. Chil. Chem. Soc. 57, 1447 (2012)

3. Meshram D.B., Bagade S.B., Tajne M.R.: J. Chromatogr. Sci. 47, 885 (2009).

4. Belal F., Sharaf El-Din M.K., Eid M.I., ElGamal R.M.: J. Chromatogr. Sci. 4, 298 (2014).

5. El-Bayoumi A., El-Shanawany A.A., El-Sadek M.E., Abd El-Sattar A.: Spectrosc. Lett. 30, 25 (1997).

6. Crego A.L., Marina M.L., Lavandera J.L.: J. Chromatogr. A 1-2, 337 (2001).

7. Heeren F., Tanner R., Theurillat R., Thormann W.: J. Chromatogr. A 745, 165 (1996).

8. Ayub A.C., Vianna-Soares C.D., Ferreira L.A.M.: J. Chromatogr. Sci. 45, 286 (2007).

9. Mistretta V., Dubois N., Denooz R., Charlier C.: Acta Clin. Belg. 1, 53 (2014)

10. Decosterd L.A.: Antimicrob. Agents Chemother. 12, 5303 (2010).

11. Ekiert R.J, Krzek J., Czekaj J.S., Hubicka U.: Acta Chromatogr. 21, 273 (2009).

12. Lima D.M., Nunes Junior, G.P., Ferri P.H., Santos S.C.: Braz. J. Pharm. Sci. 2, 223 (2005).

13. http://www.ich.org/fileadmin/public Web Site/ ICH Products/Guidelines/Quality/Q1A R2/ Step4/Q1A R2 Guideline.pdf (2003).

14. http://www.who.int/medicines/areas/quality safety/quality assurance/stblty-testing-APIsand FPPS-QAS17-694 12012017.pdf (2017).

15. Jamrógiewicz M.: Front Pharmacol. 7, 17 (2016).

16. Baertschi S.W., Jansen P.J., Alsante K.M.: in Pharmaceutical Stress Testing: Predicting Drug Degradation, $2^{\text {th }}$ Ed., Baertschi S.W., Alsante K.M., Reed R.A., p. 27, Taylor \& Francis, 2005.

17. Fingerman M.: Bioremediation of Aquatic and Terrestrial Ecosystems Chapter 8 Remediating RDX and HMX Contaminated Soil and Water. CRC Press, 2016.

18. Dash S., Patel S., Mishra B.K.: Tetrahedron 65, 707 (2009). 
19. Lotfy H.M., Al-Byoumy Abdel-Aleem A.A., Monir H.H.: J. Liq. Chromatogr. Rel. Technol. 36, 1013 (2013).

20. Dentiger P.J., Swenson Ch.: Ann. Pharmacother. 43, 485 (2009).

21. http://www.ich.org/fileadmin/public Web Site/ICH Products/Guidelines/Quality/Q2 R1/ Step4/Q2 R2 Guideline.pdf (2005)

22. Kocjan R. (Ed), Analytical Chemistry, pp. 518519, PZWL, Warszawa 2000.
23. Kryczyk A., Żmudzki P., Hubicka U.: Biomed. Chromatogr. 31, 9 (2017).

24. Kryczyk A., Żmudzki P., Koczurkiewicz P., Piotrowska J., Pękala E., Hubicka U.: J. Pharm. Biomed. Anal. 145 (2017).

25. Kryczyk A., Żmudzki P., Hubicka U.: Biomed. Chromatogr. 30, 11 (2016).

26. Ekiert R.J, Krzek J.: Curr. Issues Pharm. Med. Sci. 26, 3 (2013).

Received: 04.02. 2018 